of the sense, and this is the environment for true evolution. " $\mathrm{Na}$ profit grows where is no pleasure ta'en," says Shakespeare of education in general. Nearly all our activities depend upon sight, and the adult sight with its marvellous appreciation of space is the only condition of the sense which leads to greatest perfection of the movements in space which depend upon it, that is, in most movements of skill; and its perfect restfulness alone affords the condition best adapted for use in observation and in prolonged near eye-work.

There is abundant evidence that natural education of sight under civilised conditions needs rational help. 'The words of Ferrier, above quoted, describe the physiological basis of education, by which the human being has a share in his own creation or evolution, less maybe than we think, but enough to make very great the responsibility for failure to provide education when it is obviously needed, and when its attainment is simple.

The facts point clearly to the failure in the power to retain simultaneous vision with both eyes for near eye-work in the early years of life, and as clearly show the necessity for training to attain stability in simultaneous vision with both eyes during these early years. Provided that the natural use of both eyes is thus assured, it appears probable that the ordinary use of them will complete the education.

\title{
NOTE ON TRAUMATIC ASPHYXIA WITH OCULAR COMPLICATIONS
}

\author{
BY \\ J. Bruce Hamilton \\ SENIOR HOUSE SURGEON, ROYAL LONDON OPHTHALMIC HOSPITAL
}

R. W. R., aged 15 years, was leaving his work at 6 p.m. on September 2, 1929, when he was caught between the door and floor of a lift and his chest was severely compressed for a period of not more than 60 seconds : on this point he is very clear. He was immediately taken to hospital where he was detained two hours and then sent home. On arriving at his home at 8.45 p.m. his mother noticed that his face was swollen and that his eyes were blood-shot, and he was put immediately to bed. Next day there was marked swelling of the neck and face, both eyes were red and the patient was drowsy and could remember nothing of the accident. His eyesight did not appear to be affected. At the end of 7 days his memory had returned : at the end of 9 days all swelling had dis- 
appeared : and at the end of 4 weeks his eyes had returned to their normal colour.

On September 13, 1929, I saw the patient for the first time and he had then very extensive, symmetrical, bilateral subconjunctival haemorrhages, but no evidence whatsoever of vascular changes in his fundi. His vision right and left was 6/6.

The one outstanding feature of this case, as compared to similar cases reported, is the surprisingly short duration of the compression of the chest, which resulted in such extensive latent signs. On this question of duration, Foster Moore in his book on Medical Ophthalmology makes the following statement:-“"In some instances of traumatic asphyxia from severe compression of the chest of long duration, ocular complications may arise : ....'

\title{
SOME EARLY ROYAL OCULISTS
}

\author{
BY
}

\author{
R. R. JAMES \\ LONDON
}

EARLY last year the plate which is reproduced to illustrate this article was sent to me by $\mathrm{Mr}$. Holmes Spicer, in the hope that I might be able to furnish our readers with some account of Thomas Clarck. It had belonged to Sir Anderson Critchett and was bound in brown paper on which was stamped "Dedication Plates and Records, 1688." I am not learned in prints, but this would appear to be a rather rough wood block, and it will be seen that the name of the engraver is omitted. The first thing to settle was where the plate came from. Mr. H. E. Powell, Librarian of the Royal Society of Medicine, suggested that it was from a History of the. Bible, by Le Sieur de Royaumont, translated by J. Coughan and J. Raynor, printed for Robert Blome, 2 vols., roy. folio, 1690-98, with 238 plates. An extended research by $\mathrm{Mr}$. Harvey Bloom at the British Museum, Sion College, and the British and Foreign Bible Society, has failed to locate it. Mr. Bloom writes, "It ought to belong to Le Sieur' Royaumont's Histoire but neither edition contains the Apocrypha. I am inclined to think that plates were prepared for such a purpose but the volume never printed. Blome published no Bible."

I have drawn blank in all the usual books of reference, and in spite of the large amount of negative evidence, have decided to print what I know about three early Royal oculists, namely Thomas Clarck, 'Thomas Elles or Ellis and Paddington Macqueen. 